\title{
Risk for intravesical recurrence of bladder cancer stratified by the results on two consecutive UroVysion fluorescence in situ hybridization tests: a prospective follow-up study in Japan
}

\author{
Atsushi Ikeda ${ }^{1}$ - Takahiro Kojima ${ }^{1} \cdot$ Koji Kawai $^{1} \cdot$ Shiro Hinotsu ${ }^{2} \cdot$ Naoto Keino $^{3} \cdot K_{\text {Kenichiro Shiga }}^{4}$. \\ Hideaki Miyake ${ }^{5}$. Yasuyoshi Miyata ${ }^{6}$. Yutaka Enomoto ${ }^{7}$. Fumitaka Shimizu ${ }^{8} \cdot$ Satoshi Anai $^{9}$. \\ Hideyasu Matsuyama ${ }^{10} \cdot$ Chieko Suzuki $^{11} \cdot$ Yusuke Kanimoto $^{12} \cdot$ Keisuke Shigeta $^{13} \cdot$ Seiji Naito $^{4} \cdot$ Hideyuki Akaza $^{14}$. \\ Hiroyuki Nishiyama ${ }^{1}$
}

Received: 25 November 2019 / Accepted: 5 February 2020 / Published online: 3 March 2020

(c) The Author(s) 2020

\begin{abstract}
Background A previous comparative study in Japan has demonstrated that the two consecutive UroVysion tests are useful tools to detect the presence of bladder cancer during follow-up after transurethral resection, but they also presented their high rates of false-positive results. Here, we aimed to evaluate the relationship between the UroVysion tests and subsequent intravesical recurrence.

Methods In the previous study, patients without bladder cancer during the first analysis showed the same examination set repeated 3 months later as the second analysis. In this follow-up study, 326 patients showed negative findings confirmed on cystoscopy during the second UroVysion test. Recurrence-free survival was assessed using a median follow-up of 27 months. Results In the two consecutive UroVysion tests, 214 patients (65.6\%) showed negative UroVysion results in both tests, whereas 91 presented a positive result on either tests and 21 patients presented positive results in both tests. During the follow-up, 40 patients (12.3\%) had an intravesical recurrence with non-muscle-invasive bladder cancer. The recurrence rates in patients with negative results in both tests, those with one positive result in either tests, and those with positive results in both tests were $8.4 \%, 16.5 \%$, and $33.3 \%$, respectively. The multivariate analysis indicated that the history of bladder cancer and the consecutive UroVysion test pattern were independent risk factors for recurrence.

Conclusions Our data confirmed the effectiveness of two consecutive UroVysion tests in predicting intravesical recurrence after TURBT. Further prospective studies would help determine an appropriate interval for cystoscopy follow-up.
\end{abstract}

Keywords UroVysion · Non-muscle-invasive bladder cancer · Intravesical recurrence

Hiroyuki Nishiyama

nishiuro@md.tsukuba.ac.jp

1 Department of Urology, University of Tsukuba, 1-1-1 Tennodai, Tsukuba, Ibaraki 3058575, Japan

2 Department of Biostatistics, Sapporo Medical University, Sapporo, Japan

3 Tsukuba Clinical Research and Development Organization (T-CReDO), University of Tsukuba, Tsukuba, Japan

4 Department of Urology, Harasanshin Hospital, Fukuoka, Japan

5 Department of Urology, Hamamatsu University School of Medicine, Hamamatsu, Japan

6 Department of Urology, Nagasaki University, Nagasaki, Japan
7 Department of Urology, Mitsui Memorial Hospital, Tokyo, Japan

8 Department of Urology, Juntendo University, Tokyo, Japan

9 Department of Urology, Nara Medical University, Kashihara, Japan

10 Department of Urology, Yamaguchi University, Ube, Japan

11 Department of Urology, Anjo Kosei Hospital, Anjo, Japan

12 Department of Urology, Chutoen General Medical Center, Kakegawa, Japan

13 Department of Urology, Keio University, Tokyo, Japan

14 Strategic Investigation On Comprehensive Cancer Network, The University of Tokyo, Tokyo, Japan 


\section{Introduction}

In 2018, bladder cancer (BC) was the sixth most common cancer in men and the 17 th most common cancer in women worldwide, and 550,000 new cases occur each year [1]. Non-muscle-invasive bladder cancer (NMIBC) accounts for $75 \%$ of BC cases. In NMIBC, $50-80 \%$ of patients suffered from intravesical recurrence; of these, 15-25\% will develop muscle-invasive $\mathrm{BC}$. The high rate of intravesical recurrence and progression leads to the deterioration of the quality of life of patients [2].

Cystoscopy and urinary cytology are the most widely used examinations for monitoring BC patients. However, the sensitivity of urinary cytology, especially that for the low-grade tumor, is not sufficient. In this point, recently, the UroVysion test (UroVysion Bladder Cancer Kit:Abbot Molecular, Des Plaines IL), a multicolor fluorescence in situ hybridization technique that detects aneuploidy of chromosomes 3, 7, and 17 and the loss of 9p21 locus, showed promising results as a more sensitive tool for the initial diagnosis and monitoring in several studies conducted in Western countries [3, 4]. Moreover, in Japan, a large comparative study of two consecutive UroVysion tests enrolled 486 BC patients and demonstrated higher sensitivity of the tests than did urine cytology [5]. The UroVysion test had 50.0\% (95\% CI 35.2-64.8\%) sensitivity and $72.4 \%(68.3-76.8 \%)$ specificity. Urine cytology had $4.5 \%(0.0-10.7 \%)$ sensitivity and $99.8 \%(99.3-100.0 \%)$ specificity. However, in this study, BC was not detected in 116 patients with positive UroVysion test results (falsepositive rate $27.6 \%$ ). This may be due to the low specificity of the UroVysion test. On the other hand, there is a possibility that the positive UroVysion test reflects the presence of invisible precursor lesions in some patients. Thus, we aimed to evaluate the relationship between the previous UroVysion tests and subsequent intravesical recurrence.

\section{Patients and methods}

\section{Study design}

A total of $486 \mathrm{BC}$ patients treated with transurethral resection (TURBT) within the prior 2 years were enrolled in the previous comparative study of two consecutive UroVysion tests. Among them, two consecutive results were obtained in 399 patients. In patients who showed no suspicious findings of recurrent $\mathrm{BC}$ during the first analysis, a second set of the UroVysion test and urine cytology was performed 3 months after the first set. Patients who showed suspicious findings in the second analysis underwent histological examination of the biopsy or transurethral resection, as in the first analysis. $\mathrm{BC}$ was detected in 15 patients at the second UroVysion test, and additional 6 patients developed MIBC before initiation of the present study. As shown in Fig. 1, 52 patients were excluded from the present study, because they were lost to follow-up (35 patients), had a disagreement with the study (13 patients), and had inconclusive UroVysion test (4 patients). Resultantly, 326 patients with negative cystoscopy and cytology results were enrolled in the present study. Patients were followed for $\mathrm{BC}$ recurrence according to the protocol of each participating institution. The follow-up period was defined as the time from the second UroVysion test until the date of the last cystoscopy or the date when $\mathrm{BC}$ was diagnosed by cystoscopy or cytology. The median follow-up period was 27 months (range 1-36.4 months). All $\mathrm{BC}$ recurrences were pathologically confirmed. This study was conducted in accordance with the ethical principles of the 2013 Declaration of Helsinki and was approved by the
Fig. 1 Flow diagram of patient enrollment. $M I B$ $C$ muscle-invasive bladder cancer,TURBTtransurethral resection, $B C$ bladder cancer

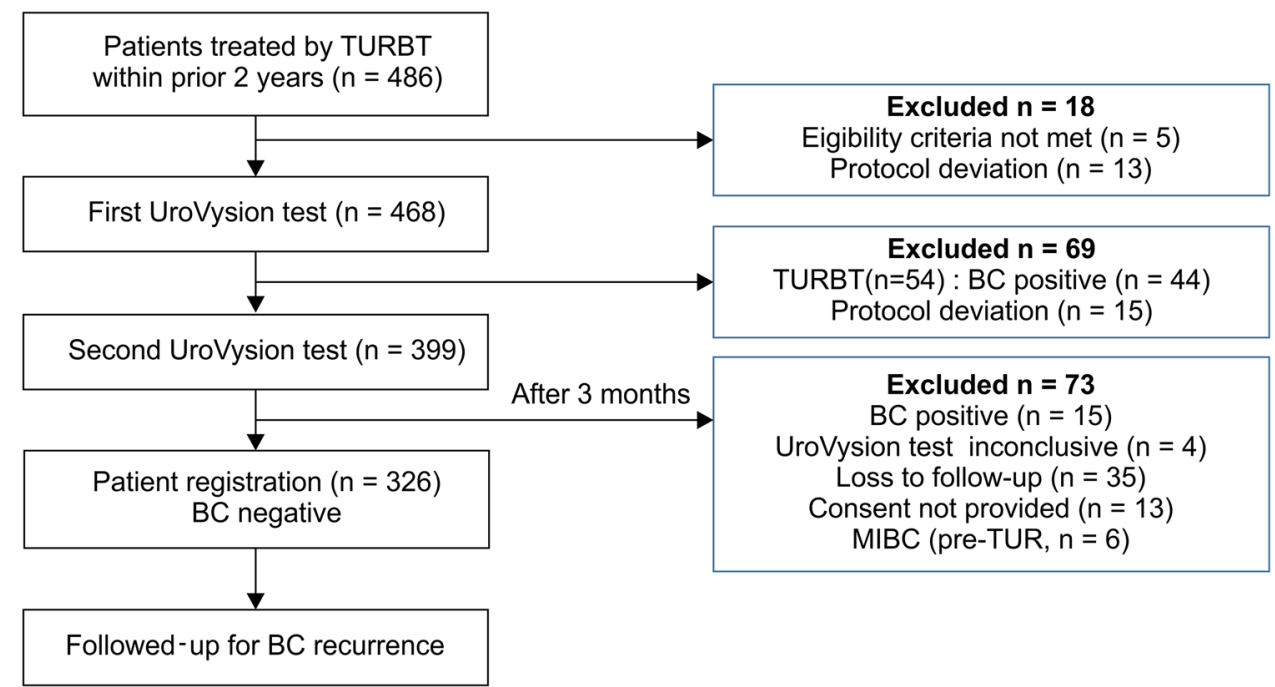


Institutional Review Board of the University of Tsukuba Hospital, which is the representative medical organization (Approval number: H28-184). We obtained written informed consent from patients and provided the option of declining the invitation to participate in the study.

\section{Statistical analysis}

Patient characteristics were compared using the Pearson's chi-square test. Recurrence-free survival (RFS) curves were estimated by the Kaplan-Meier method and compared using a log-rank test. The level of significance was set at $P<0.05$. The relative influence of different clinical factors on RFS was estimated using Cox's proportional hazards model with multiple variables. We enlisted a purposeful selection of variables in the analysis, used a $P$ value of $<0.05$, and excluded variables that were not statistically significant. Statistical analysis was performed using JMP 10.0.2 software (SAS Institute, Cary, NC).

\section{Results}

The characteristics of 326 patients are summarized in Table 1 . The median age was 71 years (range 26-91 years). The history of BC was primary in 226 patients $(69.3 \%)$ and recurrent in 100 patients $(30.7 \%)$. The initial T stage before study enrollment was Ta in $58.9 \%$ of patients, $\mathrm{T} 1$ in $31.9 \%$, and Tis in $7.1 \%$. The carcinoma in situ (CIS) was confirmed in 71 patients (21.8\%), including those with concurrent CIS.

Table 1 Patient characteristics

\begin{tabular}{|c|c|c|c|c|c|c|c|c|}
\hline & \multirow[t]{2}{*}{$N$} & \multirow[t]{2}{*}{$\%$} & \multicolumn{2}{|c|}{$\begin{array}{l}\text { Negative results in } \\
\text { both tests }(n=214)\end{array}$} & \multicolumn{2}{|c|}{$\begin{array}{l}\text { Positive result in } \\
\text { one of the tests } \\
(n=91)\end{array}$} & \multicolumn{2}{|c|}{$\begin{array}{l}\text { Positive results in } \\
\text { both tests }(n=21)\end{array}$} \\
\hline & & & $n$ & $\%$ & $n$ & $\%$ & $n$ & $\%$ \\
\hline Male & 281 & 86.2 & 184 & 86.0 & 80 & 87.9 & 17 & 81.0 \\
\hline Female & 45 & 13.8 & 30 & 14.0 & 11 & 12.1 & 4 & 19.0 \\
\hline \multicolumn{9}{|l|}{ Age, years } \\
\hline Median (range) & $71(26-91)$ & & $70(26-90)$ & & $72(40-91)$ & & $69(40-85)$ & \\
\hline \multicolumn{9}{|l|}{ History of bladder cancer } \\
\hline Primary & 226 & 69.3 & 151 & 70.6 & 61 & 67.8 & 14 & 66.7 \\
\hline Recurrent & 100 & 30.7 & 63 & 29.4 & 30 & 32.2 & 7 & 33.3 \\
\hline \multicolumn{9}{|l|}{ No. of lesions } \\
\hline Single & 151 & 46.3 & 97 & 45.3 & 44 & 48.3 & 10 & 47.6 \\
\hline Multiple & 136 & 41.7 & 90 & 42.1 & 41 & 45.1 & 5 & 23.8 \\
\hline Cannot be evaluated & 39 & 12.0 & 27 & 12.6 & 6 & 6.6 & 6 & 28.6 \\
\hline \multicolumn{9}{|l|}{ Grade $^{\mathrm{a}}$} \\
\hline Low grade & 138 & 41.9 & 97 & 45.3 & 30 & 33.0 & 11 & 52.4 \\
\hline High grade & 141 & 44.0 & 90 & 42.1 & 44 & 48.3 & 7 & 33.3 \\
\hline Cannot be evaluated & 47 & 14.1 & 27 & 12.6 & 17 & 18.7 & 3 & 14.3 \\
\hline \multicolumn{9}{|l|}{ TNM stage } \\
\hline $\mathrm{Ta}$ & 192 & 58.9 & 129 & 60.3 & 48 & 52.7 & 15 & 71.4 \\
\hline $\mathrm{T} 1$ & 104 & 31.9 & 68 & 31.8 & 33 & 36.3 & 3 & 14.3 \\
\hline Tis & 23 & 7.1 & 14 & 6.5 & 6 & 6.6 & 3 & 14.3 \\
\hline Cannot be evaluated & 7 & 2.1 & 3 & 1.4 & 4 & 4.4 & 0 & 0 \\
\hline \multicolumn{9}{|l|}{ Presence of CIS } \\
\hline No & 255 & 78.2 & 168 & 78.5 & 70 & 76.9 & 17 & 81.0 \\
\hline Yes & 71 & 21.8 & 46 & 21.5 & 21 & 23.1 & 4 & 19.0 \\
\hline \multicolumn{9}{|l|}{ Smoking } \\
\hline Current & 60 & 18.4 & 39 & 18.2 & 17 & 18.7 & 4 & 19.1 \\
\hline Former & 112 & 34.4 & 71 & 33.2 & 31 & 34.0 & 10 & 47.6 \\
\hline Never & 91 & 27.9 & 62 & 29.0 & 24 & 26.4 & 5 & 23.8 \\
\hline Unknown & 63 & 29.3 & 42 & 19.6 & 19 & 20.9 & 2 & 9.5 \\
\hline
\end{tabular}

There was no significant difference in the distribution of clinical characteristics CIS carcinoma in situ, TNM tumor-node-metastasis

${ }^{a} 1973$ World Health Organization classification 
In the two consecutive UroVysion tests, 214 patients $(65.6 \%)$ presented negative results for both tests, whereas 91 patients (27.9\%) presented positive results in one of the tests, and 21 patients (6.4\%) showed positive results in both tests. As shown in Table 1, there was no significant difference in the distribution of clinical characteristics among patients with negative results in both tests, those with one positive result in one of the tests, and those with positive results in both tests.

Intravesical BC recurrence was observed in $40(12.3 \%)$ out of the 326 patients during the follow-up period (Table 2). The pathological diagnoses of recurrent tumors were lowgrade Ta tumor in 20 patients $(6.1 \%)$, high-grade Ta tumor, $\mathrm{T} 1$ tumor, or CIS in 15 patients (4.6\%), and $\geq \mathrm{T} 2$ tumor in three patients (0.9\%). Eighteen out of 214 patients (8.4\%) with negative results for both UroVysion tests had tumor recurrence. The recurrence rates of patients with positive results in one of the tests and positive results in both tests were higher (16.5\% and $33.3 \%$, respectively). Resultantly, in total, the 2-year RFS rate of the patients with positive results in both tests was $71.4 \%$, which was significantly lower than that of patients with negative results in both tests $(93.5 \%)$ and those with positive results in one of the tests $(87.9 \%)$ (Fig. 2, $P=0.0007$ ). The median interval to recurrence in patients with positive results in both tests was 9.0 months, which was shorter than that of patients with positive results in one of the tests (19.6 months) and those with negative results in both tests (23.5 months).
Table 2 Recurrence rate and pathological diagnosis of recurrent tumor according to the UroVysion test pattern

\begin{tabular}{lllll}
\hline & Total & $\begin{array}{l}\text { Negative results in } \\
\text { both tests }\end{array}$ & $\begin{array}{l}\text { Positive result in one } \\
\text { of the tests }\end{array}$ & $\begin{array}{l}\text { Positive } \\
\text { results in } \\
\text { both tests }\end{array}$ \\
\hline $\begin{array}{l}\text { No. of patients } \\
\text { No. of recurrences (\%) }\end{array}$ & 326 & 214 & 91 & 21 \\
TNM stage, Grade (\%) & $40(12.3)$ & $18(8.4)$ & $15(16.5)$ & $7(33.3)$ \\
Ta low & $20(50)$ & $9(50)$ & $8(53.3)$ & $3(42.9)$ \\
Ta high/T1/Tis & $15(37.5)$ & $8(44.4)$ & $4(26.7)$ & $3(42.9)$ \\
T2 or greater & $3(7.5)$ & $1(5.6)$ & $1(0.7)$ & $1(14.2)$ \\
Cannot be evaluated & $2(5)$ & 0 & $2(1.3)$ & 0 \\
\hline
\end{tabular}

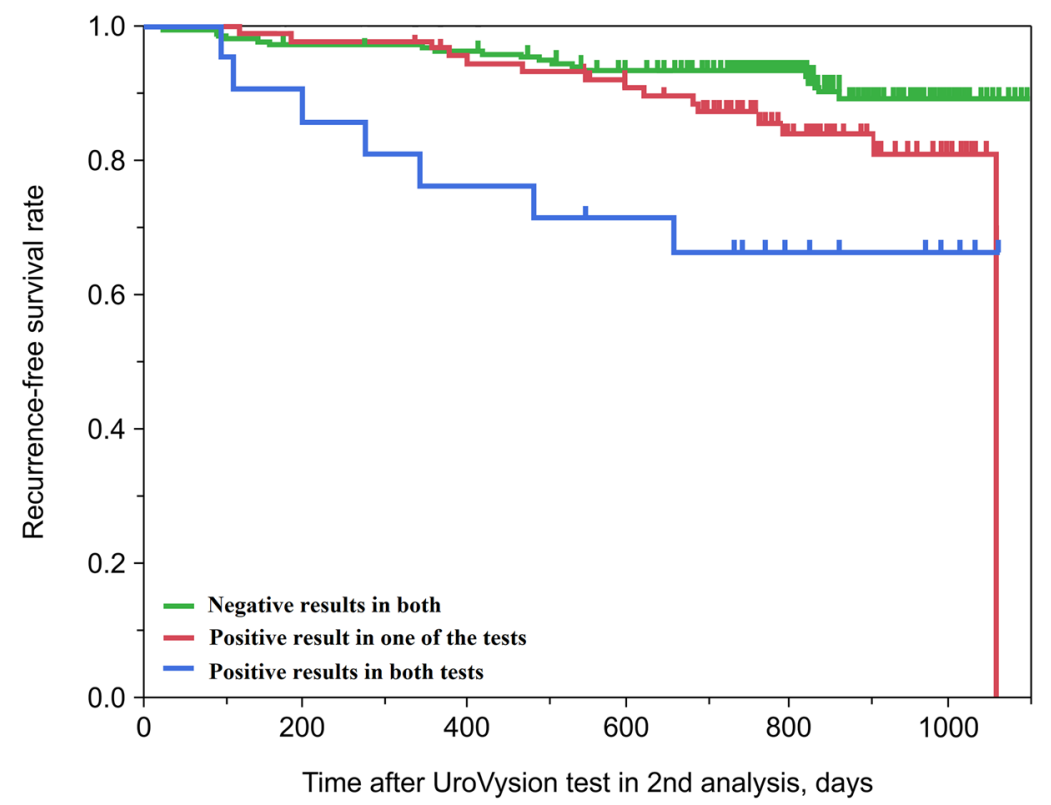

Fig. 2 Recurrence-free survival rate stratified by the pattern of the results of the two consecutive UroVysion tests
Number of patients at risk:

$\begin{array}{lrrrrrr}\text { Negative results in both } & 214 & 206 & 203 & 190 & 113 & 27 \\ \text { Positive result in one of the tests } & 91 & 88 & 83 & 78 & 48 & 10 \\ \text { Positive results in both tests } & 21 & 19 & 17 & 15 & 8 & 4\end{array}$

Log-rank test: $P=0.0007$ 
In the Cox proportional hazards model, as shown in Table 3, the univariate analysis showed that the history of $\mathrm{BC}$, $\mathrm{T}$ stage, and consecutive UroVysion test pattern were associated with a higher risk for subsequent recurrence. The other variables were not significant predictors. On the basis of the results of the univariate analysis, we performed a multivariate analysis using the following factors: the history of BC, T stage, and consecutive UroVysion test pattern. The results indicated that the history of $\mathrm{BC}$ and consecutive UroVysion test patterns were independent risk factors for recurrence.

\section{Discussion}

In Japan, a prospective comparative study showed that the UroVysion test provided higher sensitivity than urine cytology in detecting BC during follow-up after TURBT [5]. Based on these outcomes, UroVysion was approved in Japan in 2017 as a genetic test for the diagnosis of BC recurrence. Still, the indication is limited to patients having CIS and also the test frequency of two times within 2 years after TURBT. Despite the high sensitivity, a Japanese study also presented the high false-positive rate of

Table 3 Univariate and multivariate Cox proportional hazards regression analyses for recurrence after the UroVysion test in the second analysis

\begin{tabular}{|c|c|c|c|c|c|}
\hline \multirow[t]{2}{*}{ Variable $(n)$} & \multirow{2}{*}{$\begin{array}{l}\text { Number of } \\
\text { patients }\end{array}$} & \multicolumn{2}{|l|}{ Univariate } & \multicolumn{2}{|l|}{ Multivariate } \\
\hline & & HR $(95 \%$ CI $)$ & $P$ value* & $\mathrm{HR}(95 \% \mathrm{CI})$ & $P$ value* \\
\hline \multicolumn{6}{|l|}{ Age, years } \\
\hline$<70$ & 160 & 1 (reference) & 0.5422 & & \\
\hline $71<$ & 166 & $0.824(0.437-1.53)$ & & & \\
\hline \multicolumn{6}{|l|}{ Sex } \\
\hline Female & 45 & 1 (reference) & 0.166 & & \\
\hline Male & 281 & $2.10(0.758-8.71)$ & & & \\
\hline \multicolumn{6}{|l|}{ History of bladder cancer } \\
\hline Primary & 226 & 1 (reference) & 0.00250 & 1 (reference) & 0.0069 \\
\hline Recurrent & 100 & $2.63(1.41-4.94)$ & & $2.39(1.27-4.51)$ & \\
\hline \multicolumn{6}{|l|}{ No. of lesions } \\
\hline Single & 151 & 1 (reference) & 0.0650 & & \\
\hline Multiple & 136 & $1.87(0.926-3.94)$ & & & \\
\hline \multicolumn{6}{|l|}{ T stage } \\
\hline $\mathrm{Ta}$ & 192 & 1 (reference) & & 1 (reference) & \\
\hline $\mathrm{T} 1$ & 104 & $0.502(0.200-1.11)$ & 0.0899 & $0.566(0.224-1.26)$ & 0.1708 \\
\hline Tis & 23 & $2.57(1.02-5.70)$ & 0.0459 & $2.16(0.848-4.82)$ & 0.1012 \\
\hline \multicolumn{6}{|l|}{ Grade } \\
\hline Low & 138 & 1 (reference) & 0.214 & & \\
\hline High & 141 & $0.809(0.389-1.67)$ & & & \\
\hline \multicolumn{6}{|l|}{ Presence of CIS } \\
\hline No & 255 & 1 (reference) & 0.346 & & \\
\hline Yes & 71 & $1.41(0.674-2.74)$ & & & \\
\hline \multicolumn{6}{|l|}{ Postoperative intravesical therapy } \\
\hline No & 97 & 1 (reference) & 0.866 & & \\
\hline BCG & 116 & $0.831(0.376-1.85)$ & & & \\
\hline Chemotherapy & 113 & $0.990(0.463-2.16)$ & & & \\
\hline \multicolumn{6}{|l|}{ Smoking } \\
\hline Never & 91 & 1 (reference) & 0.640 & & \\
\hline Former & 112 & $1.34(0.608-3.08)$ & & & \\
\hline Current & 60 & $1.39(0.554-3.46)$ & & & \\
\hline \multicolumn{6}{|c|}{ Combination of two consecutive analyses of UroVysion tests } \\
\hline Negative results in both tests & 214 & 1 (reference) & & 1 (reference) & \\
\hline Positive result in one of the tests & 91 & $2.02(1.00-4.02)$ & 0.0488 & $2.06(1.01-4.13)$ & 0.0467 \\
\hline Positive results in both tests & 21 & $4.71(1.83-10.8)$ & 0.0024 & $4.15(1.59-9.65)$ & 0.0051 \\
\hline
\end{tabular}

$* P<0.05$ was considered statistically significant 
the UroVysion test. Generally, false-positive results in the UroVysion test can be due to the umbrella cells, often appearing as chromosome tetraploid [6], or heteroploidy appearing due to human polyomavirus infection [7]. Although several kinds of mechanism for true false-positive results have existed, there is a possibility that the positive UroVysion test results reflect the presence of invisible precursor lesions in some patients.

To test the hypothesis, there are several long-term followup studies after the UroVysion test. These studies showed that patients with positive UroVysion test have a significantly higher recurrence rate. However, previous studies were limited, because they had a relatively small cohort size, and more importantly, the UroVysion results were disclosed to the attending physician $[4,8,9]$. In this point of view, the present study involved 326 patients, and the results of the UroVysion tests were not revealed to the attending physician. Furthermore, the UroVysion test was conducted twice with an interval of approximately 3 months, which confirmed that the recurrence rate increased depending on the test result pattern, with the rate increasing in order from patients with negative results in both tests $(8.4 \%)$, those with positive results in one of the tests $(16.5 \%)$, and those with positive results in both tests (33.3\%). Resultantly, the 2-year RFS rate of those with positive results in both tests was $71.4 \%$, which was significantly lower than that of patients with negative results in both tests $(93.5 \%)$ and those with positive results in one of the tests $(87.9 \%)$. The multivariate analysis indicated that $\mathrm{T}$ stage and the consecutive UroVysion test pattern were independent risk factors for recurrence. Given the positive rates of urinary cytology were relatively low in terms of recurrence without CIS, the two consecutive UroVysion tests are considered to be useful tools for predicting this type of recurrence.

A cystoscopy is an essential tool for BC follow-up, but there has always been room for debate on the appropriate frequency of cystoscopic examinations. The present study showed that the recurrence rate was higher in patients with positive results in both tests, and these patients developed recurrence with a shorter interval (Fig. 2). The finding suggests the possibility of precision management with the setting of the intervals of cystoscopy based on the results of the UroVysion test.

This study has several limitations. First, patients were followed for BC recurrence according to the protocol of each participating institution. Second, almost all patients underwent conventional white light cystoscopy, but not a photodynamic diagnosis or narrow-band imaging examination during followup. Therefore, further study is needed to clarify the role of UroVysion tests in the era of high-resolution endoscopes. Despite these limitations, our data confirmed the effectiveness of two consecutive UroVysion tests in predicting intravesical recurrence after TURBT. Further prospective studies would help determine an appropriate interval for cystoscopy follow-up.

Acknowledgements This study was supported by Abbott Japan Co., Ltd., Tokyo, Japan. We thank the members of the Tsukuba Clinical Research and Development Organization (T-CReDO) at the University of Tsukuba for their critical advice in conducting the study and data management during the study period.

Author contributions HA designed the study, and AI wrote the initial draft of the manuscript. TK, KK, and SH contributed to the analysis and interpretation of data and assisted in the preparation of the manuscript. All other authors have contributed to data collection and interpretation and critically reviewed the manuscript. All authors approved the final version of the manuscript and agreed to be accountable for all aspects of the work in ensuring that questions related to the accuracy or integrity of any part of the work are appropriately investigated and resolved.

\section{Compliance with ethical standards}

Conflict of interest The following author received financial support from Abbott Japan: HA, consulting fee, and travel support.

Open Access This article is licensed under a Creative Commons Attribution 4.0 International License, which permits use, sharing, adaptation, distribution and reproduction in any medium or format, as long as you give appropriate credit to the original author(s) and the source, provide a link to the Creative Commons licence, and indicate if changes were made. The images or other third party material in this article are included in the article's Creative Commons licence, unless indicated otherwise in a credit line to the material. If material is not included in the article's Creative Commons licence and your intended use is not permitted by statutory regulation or exceeds the permitted use, you will need to obtain permission directly from the copyright holder. To view a copy of this licence, visit http://creativecommons.org/licenses/by/4.0/.

\section{References}

1. Bray F, Ferlay J, Soerjomataram I et al (2018) Global Cancer Statistics 2018: GLOBOCAN estimates of incidence and mortality worldwide for 36 cancers in 185 countries. CA Cancer J Clin 68:394-424

2. Sievert KD, Amend B, Nagele U et al (2009) Selection of patients and benefit of immediate radical cystectomy for non-muscle invasive bladder cancer. World J Urol 27:295-300

3. Sarosdy MF, Schellhammer P, Bokinsky G et al (2002) Clinical evaluation of a multi-target fluorescent in situ hybridization assay for detection of bladder cancer. J Urol 168:1950-1954

4. Kipp BR, Karnes RJ, Brankley SM et al (2005) Monitoring intravesical therapy for superficial bladder cancer using fluorescence in situ hybridization. J Urol 173:401-404

5. Kojima T, Nishiyama H, Ozono $\mathrm{S}$ et al (2018) Clinical evaluation of two consecutive UroVysion fluorescence in situ hybridization tests to detect intravesical recurrence of bladder cancer: a prospective blinded comparative study in Japan. Int J Clin Oncol 23:1140-1147

6. Zellweger T, Benz G, Cathomas G et al (2006) Multi-target fluorescence in situ hybridization in bladder washings for prediction of recurrent bladder cancer. Int J Cancer 119:1660-1665

7. Kipp BR, Sebo TJ, Griffin MD et al (2005) Analysis of polyomavirus-infected renal transplant recipients' urine specimens: correlation of routine urine cytology, fluorescence in situ hybridization, and digital image analysis. Am J Clin Pathol 124:854-861

8. Seideman C, Canter D, Kim P et al (2015) Multicenter evaluation of the role of UroVysion FISH assay in surveillance of patients with 
bladder cancer: does FISH positivity anticipate recurrence? World J Urol 33:1309-1313

9. Yoder BJ, Skacel M, Hedgepeth R et al (2007) Reflex UroVysion testing of bladder cancer surveillance patients with equivocal or negative urine cytology: a prospective study with focus on the natural history of anticipatory positive findings. Am J Clin Pathol 127:295-301
Publisher's Note Springer Nature remains neutral with regard to jurisdictional claims in published maps and institutional affiliations. 